Portland State University

PDXScholar

\title{
The Effects of Long-Duration Subduction Earthquakes on Inelastic Behavior of Bridge Pile Foundations Subjected to Liquefaction-Induced Lateral Spreading
}

Jonathan Nasr

Atlas Geotechnical

Arash Khosravifar

Portland State University, karash@pdx.edu

Follow this and additional works at: https://pdxscholar.library.pdx.edu/cengin_fac

Part of the Civil Engineering Commons, Environmental Engineering Commons, and the Structural Engineering Commons

Let us know how access to this document benefits you.

\section{Citation Details}

Nasr, Jonathan and Khosravifar, Arash, "The Effects of Long-Duration Subduction Earthquakes on Inelastic Behavior of Bridge Pile Foundations Subjected to Liquefaction-Induced Lateral Spreading" (2018). Civil and Environmental Engineering Faculty Publications and Presentations. 450.

https://pdxscholar.library.pdx.edu/cengin_fac/450

This Post-Print is brought to you for free and open access. It has been accepted for inclusion in Civil and Environmental Engineering Faculty Publications and Presentations by an authorized administrator of PDXScholar. Please contact us if we can make this document more accessible: pdxscholar@pdx.edu. 


\title{
The Effects of Long-Duration Subduction Earthquakes on Inelastic Behavior of Bridge Pile Foundations Subjected to Liquefaction-Induced Lateral Spreading
}

\author{
Jonathan Nasr, ${ }^{1}$ and Arash Khosravifar, Ph.D., P.E., M.ASCE ${ }^{2}$ \\ ${ }^{1}$ Atlas Geotechnical, Santa Cruz, CA 95060; e-mail: Jonathan@ AtlasGeotechnical.com \\ ${ }^{2}$ Department of Civil and Environmental Engineering, Portland State University, Portland, OR \\ 97201; e-mail: karash@pdx.edu
}

\begin{abstract}
Effective-stress nonlinear dynamic analyses (NDA) were performed for a large-diameter reinforced concrete $(\mathrm{RC})$ pile in multi-layered liquefiable sloped ground. The objective was to assess the effects of earthquake duration on the combination of inertia and liquefaction-induced lateral spreading. A parametric study was performed using input motions from subduction and crustal earthquakes covering a wide range of motion durations. The NDA results showed that the pile head displacements increased under liquefied conditions, compared to nonliquefied conditions, due to liquefaction-induced lateral spreading. The NDA results were used to develop a displacement-based equivalent static analysis (ESA) method that combines inertial and lateral spreading loads for estimating elastic and inelastic pile demands.
\end{abstract}

\section{INTRODUCTION}

Past earthquakes indicate that liquefaction-induced lateral spreading is a major cause of collapse for pile foundations. The design guidelines to combine inertia and liquefaction-induced kinematics vary. For example, AASHTO (2014) recommends designing piles for simultaneous effects of inertia and lateral spreading only for large magnitude earthquakes (M>8). ASCE/COPRI 61 (2014) assumes independent effects of these loads for port facilities, although it recommends evaluating this assumption on a project-specific basis. Caltrans (2012) and ODOT (Ashford et al. 2012) recommend combining $100 \%$ lateral spreading with 50\% inertia. WSDOT (2015), on the other hand, recommends $100 \%$ lateral spreading with $25 \%$ inertia.

The objective of this study was to evaluate the effects of strong motion duration on inelastic deformations of piles subjected to combined inertia and liquefaction-induced lateral spreading. These effects are particularly important in the Pacific Northwest where the expected magnitude 9 Cascadia Subduction Zone earthquake is estimated to produce motions with duration as long as 4 minutes. This paper will, first, present the development of ground motions for two representative sites in Oregon with contributions from the Cascadia Subduction Zone (expected to produce longduration motions) and crustal sources (expected to produce short-duration motions). Then, the development of a 2-D finite-element dynamic model will be presented. The FE model was used in 
a parametric study to perform nonlinear dynamic analyses (NDA) covering a range of strong motion durations. The pile demands from NDA were be used to develop new ESA procedures.

The approach adopted in this study was to perform NDA to evaluate the accuracy of developed ESA procedures. The NDA were performed on a large diameter (2-meter) RC pile under liquefied and nonliquefied conditions. The maximum pile head displacement was used as a measure of pile performance to compare ESA and NDA results.

\section{NONLINEAR DYNAMIC ANALYSIS (NDA)}

Finite-Element (FE) Model. Two-dimensional effective-stress nonlinear dynamic analyses (NDA) were performed in OpenSees Finite-Element (FE) software (Mazzoni et al. 2009). As shown in Figure 1a, the FE model included three components: (1) A 2-D soil column to simulate the free-field site response. The liquefiable sand was modeled using the Pressure-DependentMulti-Yield (PDMY02) constitutive model (Yang et al. 2003). An example of the cyclic response of loose sand is shown in Figure 1b; (2) The RC shaft (CIDH pile) was modeled using fiber sections and nonlinear-beam-column elements which capture formation of a plastic hinge in the pile as shown in Figure 1c; (3) Special soil-pile interface elements (py springs for lateral resistance, $t z$ springs for skin friction, and qz springs for end-bearing) were used to connect soil and pile nodes together. The soil spring properties were selected based on recommendations of API (2000). The strength and stiffness of these springs change in proportion to the excess-pore-water pressure ratio in the liquefying soil as shown in Figure 1b. These springs have proven to be effective in capturing the first-order effects of liquefaction during dynamic analyses (Brandenberg et al. 2013). More details on the FE model and input parameters are provided in Khosravifar et al. (2014a). The ground motions were applied as outcrop motions using the compliant-base procedure per Mejia and Dawson (2006).

(a)

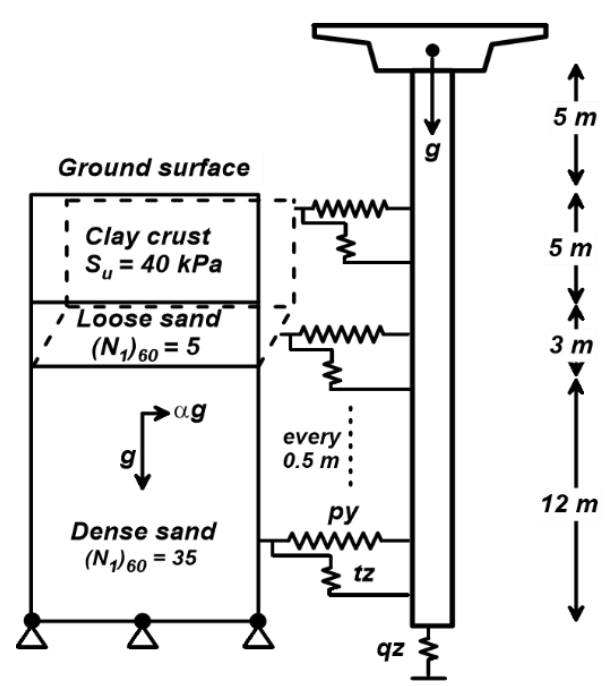

(b)

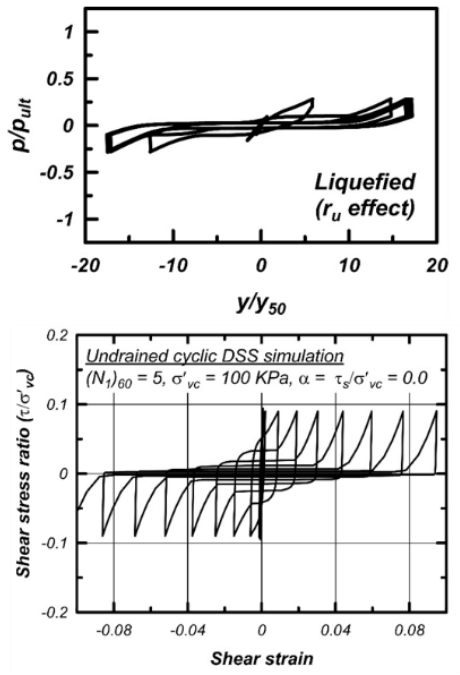

(c)

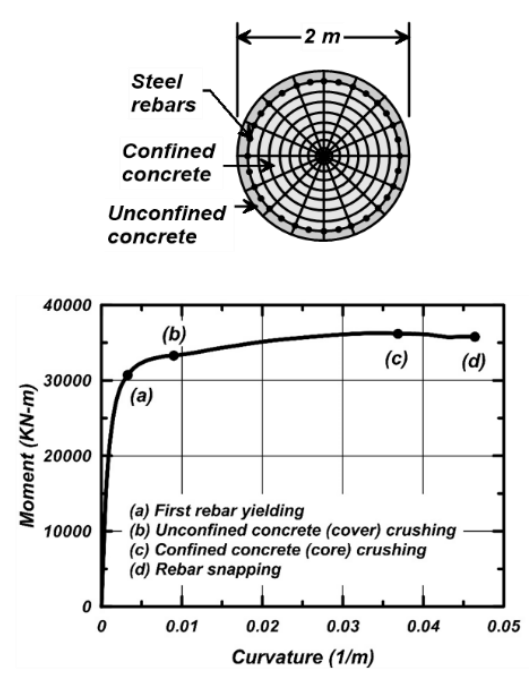

Figure 1. (a) Schematic of the finite-element (FE) model, (b) examples of soil element and soil spring cyclic responses in the liquefied layer, (c) example of nonlinear pile response. 
The subsurface condition analyzed in this study consisted of a typical three-layer profile: a 5-meter nonliquefying crust with undrained shear strength of $\mathrm{Su}=40 \mathrm{kPa}$, overlying a 3-meter loose liquefying sand with $\left(\mathrm{N}_{1}\right)_{60}=5$, overlying a nonliquefying dense sand with $\left(\mathrm{N}_{1}\right)_{60}=35$. The RC pile was 2 meters in diameter with 20-meter embedment and 5-meter height above the ground. The pile head to superstructure connection was free to rotate. The concrete strength was f'c $=44.8$ $\mathrm{MPa}$. The superstructure dead load was $7 \mathrm{MN}$, corresponding to approximately $5 \% \mathrm{f}^{\prime} \mathrm{c}^{*} \mathrm{Ag}$.

The dynamic analyses (NDA) were performed for two conditions: (1) liquefied slopedground condition with $10 \%$ slope $(\alpha=0.1)$, and (2) nonliquefied level-ground condition where pore-water pressure generation was precluded.

Ground Motions. Seismic hazard analyses were conducted for two different sites in Oregon, the coastal city of Astoria and the downtown region of Portland. Based on the USGS seismic hazard deaggregation tool, the seismic hazard in Astoria is almost entirely dominated by the Cascadia Subduction Zone (CSZ), while the seismic hazard in Portland is dominated by CSZ and a nearby crustal fault known as the Portland Hills Fault (PHF). For each site, two design spectra were developed: a 975-year design spectrum per AASHTO (2014) and an $\mathrm{MCE}_{\mathrm{R}}$ spectrum per ASCE 7-10. The target spectra were developed for site class B/C (Vs30 $760 \mathrm{~m} / \mathrm{s})$ as input for the sitespecific NDA, and are shown in Figure 2.

Seven (7) ground motions were selected for each site considering fault mechanism, magnitude, shear wave velocity at the recording station, and source to site distance. Each suite of seven motions was scaled to collectively match the respective target spectrum. Additionally, the selected ground motions for the Portland site were spectrally matched to both target spectra. The benefit of spectrally matching motions was that the frequency content of the motions is somewhat normalized to the given target spectrum and the significant duration becomes the primary differentiator among the input motions. A total of 42 time histories were used in this study. Details on ground motions selection, scaling and matching are provided in Nasr (2017).

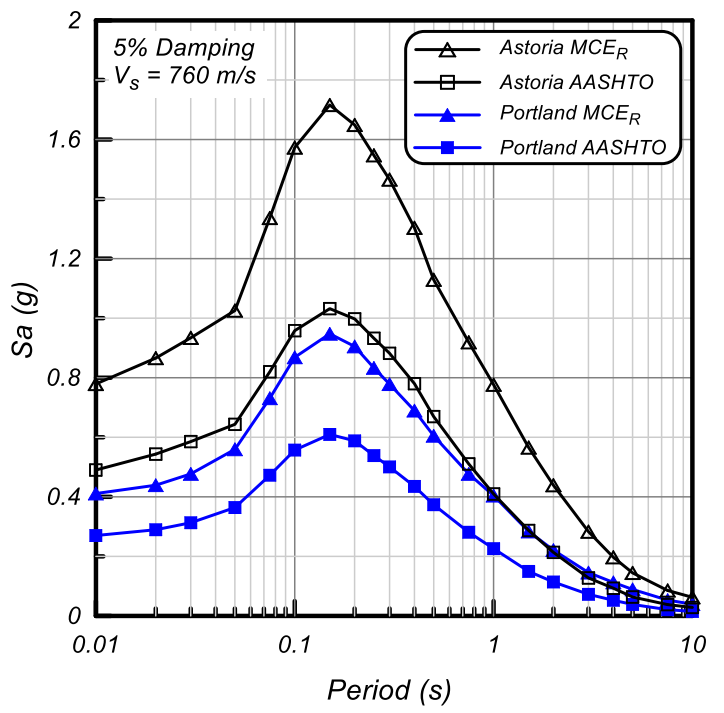

Figure 2. Target spectra developed for MCER (ASCE 7-10) and 975-year (AASHTO 2014) design levels for two sites in Portland and Astoria, OR 


\section{Representative Results from Nonlinear Dynamic Analyses (NDA)}

Figure 3 shows results of NDA from all 42 input motions. The figure compares the maximum pile head displacements between liquefied sloped-ground conditions (combined inertia and kinematics) and nonliquefied level-ground conditions (inertia only). Pile displacements are larger in the liquefied condition compared to the nonliquefied condition which indicates that pile displacements cannot be enveloped by merely accounting for the effects of inertia only or lateral spreading only. This finding is contrary to the recommendations of MCEER/ATC (2003) that suggests designing piles for the envelope of inertia and kinematics separately. These findings are aligned with the results of other recent studies, such as Boulanger et al. (2007).

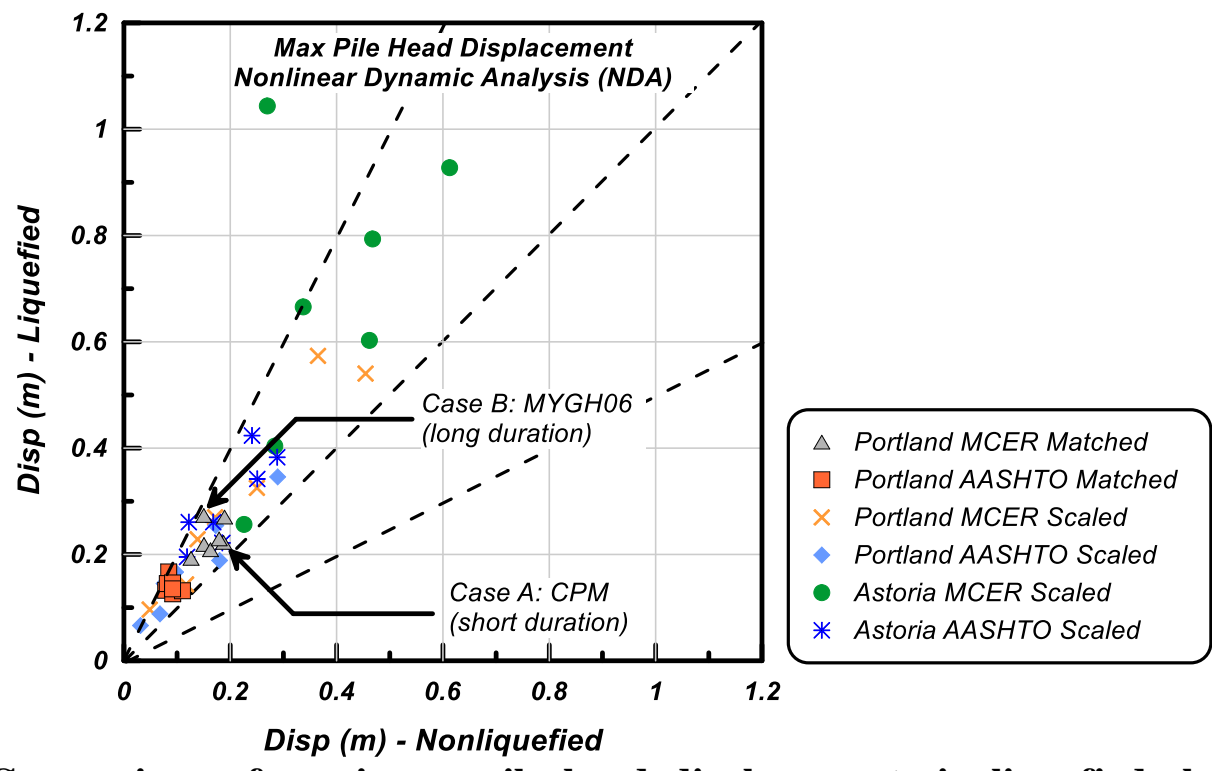

Figure 3. Comparison of maximum pile head displacements in liquefied sloped-ground versus nonliquefied level-ground conditions from nonlinear dynamic analyses (NDA)

Two cases are selected for further investigation and their dynamic responses are shown in Figures 4 and 5. Case A corresponds to 1992 Cape Mendocino EQ (CPM station) which is a crustal short-duration motion (D5-95 = $5 \mathrm{sec}$ ). Case B corresponds to 2011 Tohoku EQ (MYGH06 station) which is a subduction long-duration motion (D5-95 $=77 \mathrm{sec}$ ). Both motions were spectrally matched to $\mathrm{MCE}_{\mathrm{R}}$ design spectra for the Portland site. Therefore, both motions have similar response spectra at rock elevation. The ground surface spectra of the two motions at the natural period of the structure ( $1.3 \mathrm{sec}$ in nonliquefied conditions) are also very similar as shown in Figure 5. As a result, both motions result in similar maximum pile head displacements in the nonliquefied condition $(0.15 \mathrm{~m}$ in MYGH06 and $0.19 \mathrm{~m}$ in CPM). However, the maximum pile head displacement in liquefied conditions is increased in the case of MYGH06 $(0.27 \mathrm{~m})$ compared to CPM $(0.22 \mathrm{~m})$. To quantify this increase, we developed the parameter $\mathrm{C}_{\Delta}$ as defined in Equation 1 below:

$$
\Delta_{\text {Liq }}=\Delta_{\mathrm{LS}}+\mathrm{C}_{\Delta} * \Delta_{\text {Nonliq }}
$$


(a) Ground Surface Displacement
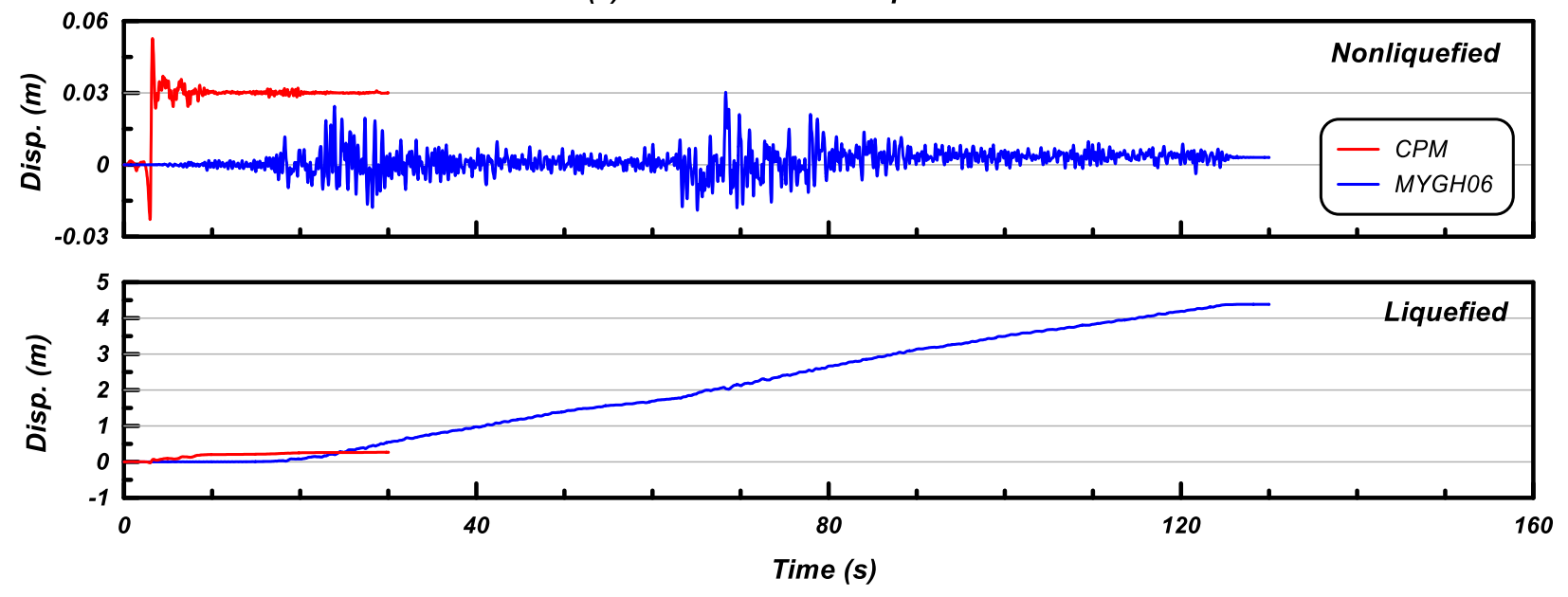

(b) Excess Pore Water Pressure in Loose Sand Layer

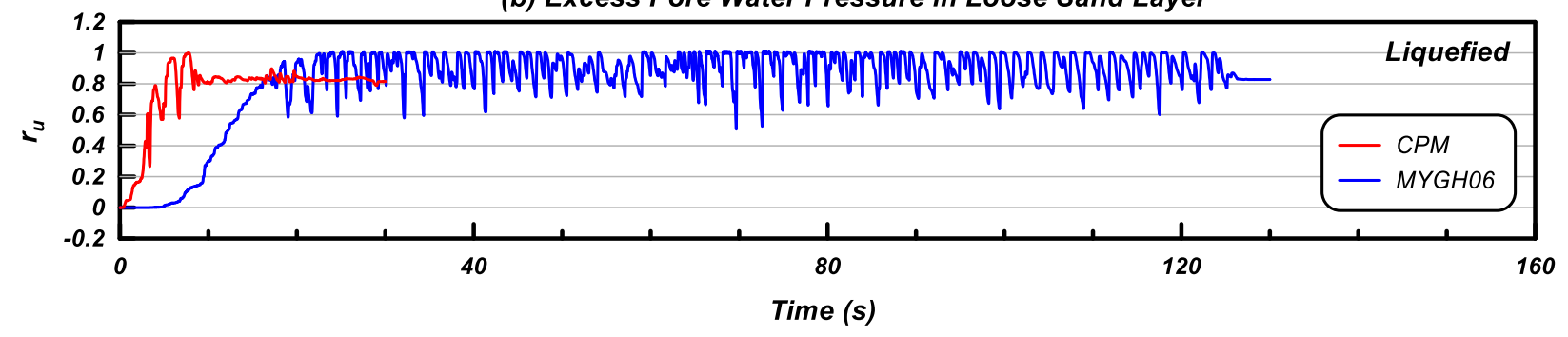

(c) Pile Head Displacement
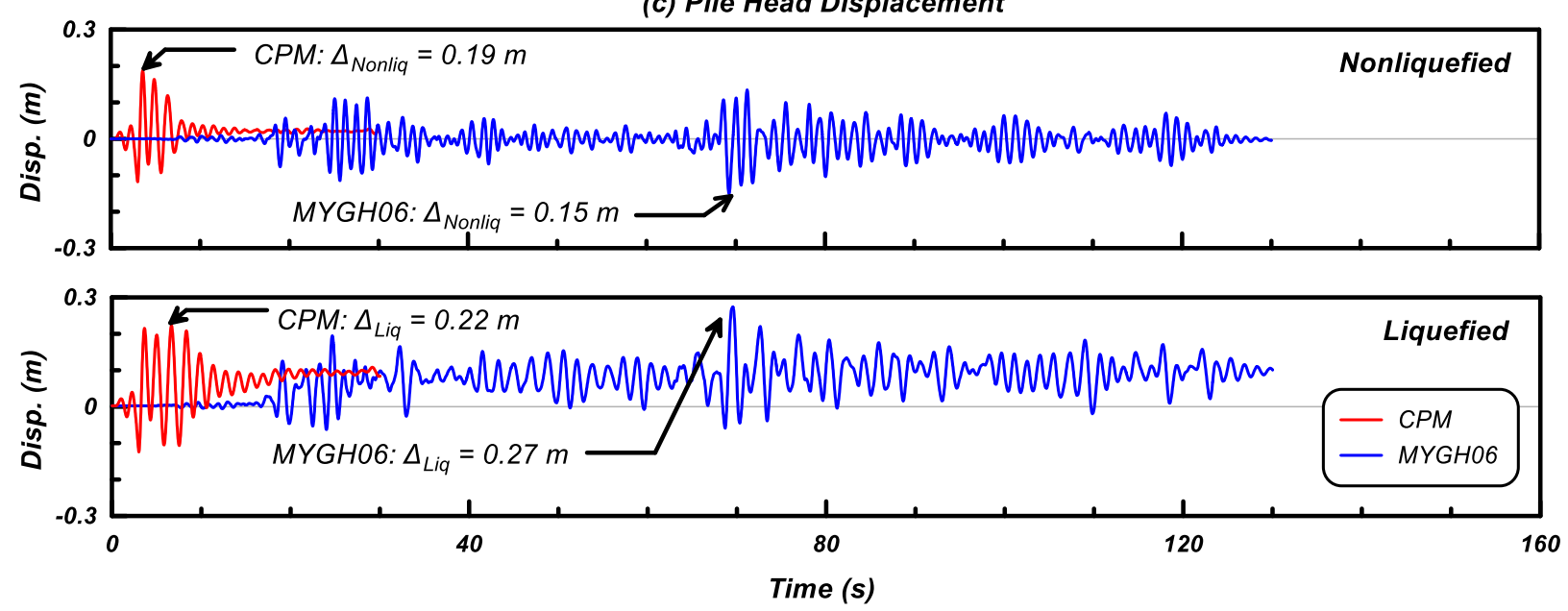

(d) Input Outcrop Motion

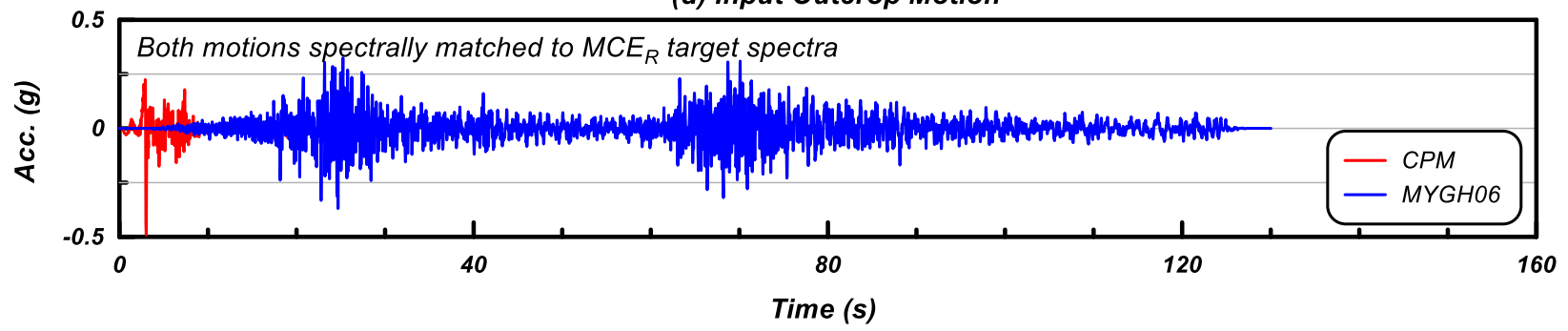

Figure 4. Representative NDA results for 1992 Cape Mendocino EQ CPM Station (short duration) and 2011 Tohoku EQ MYGH06 Station (long duration) motions 
where $\Delta_{\text {Liq }}$ and $\Delta_{\text {Nonliq }}$ are the pile head displacements in the liquefied condition (combined inertia and kinematics) and nonliquefied condition (inertia only) respectively. $\Delta_{\mathrm{LS}}$ is the pile head displacement due to kinematic demands only, which can be estimated by applying soil displacements to the end node of p-y springs. We estimated $\Delta_{\mathrm{LS}}$ to be equal to $0.03 \mathrm{~m}$ for CPM and $0.04 \mathrm{~m}$ for MYGH06. Consequently, the $\mathrm{C}_{\Delta}$ factor is calculated as 1.5 for MYGH06 (longduration) and 1.0 for CPM (short-duration). The larger $\mathrm{C}_{\Delta}$ implies that the combination of inertia and kinematics amplify pile demands. This amplification does not appear to be related to the site response, as the ground surface spectra at the natural period of the structure $(1.9 \mathrm{sec}$ in liquefied condition) are very similar as shown in Figure 5. We attributed this amplification to strong motion duration.

Figure 6 illustrates why inelastic demands are amplified in long-duration motions for piles subjected to the combination of inertia and lateral spreading loads. This figure compares momentcurvature in the plastic hinge for CPM and MYGH06. The incremental yielding in pile (ratcheting) increased inelastic demands during the long-duration MYGH06 motion.
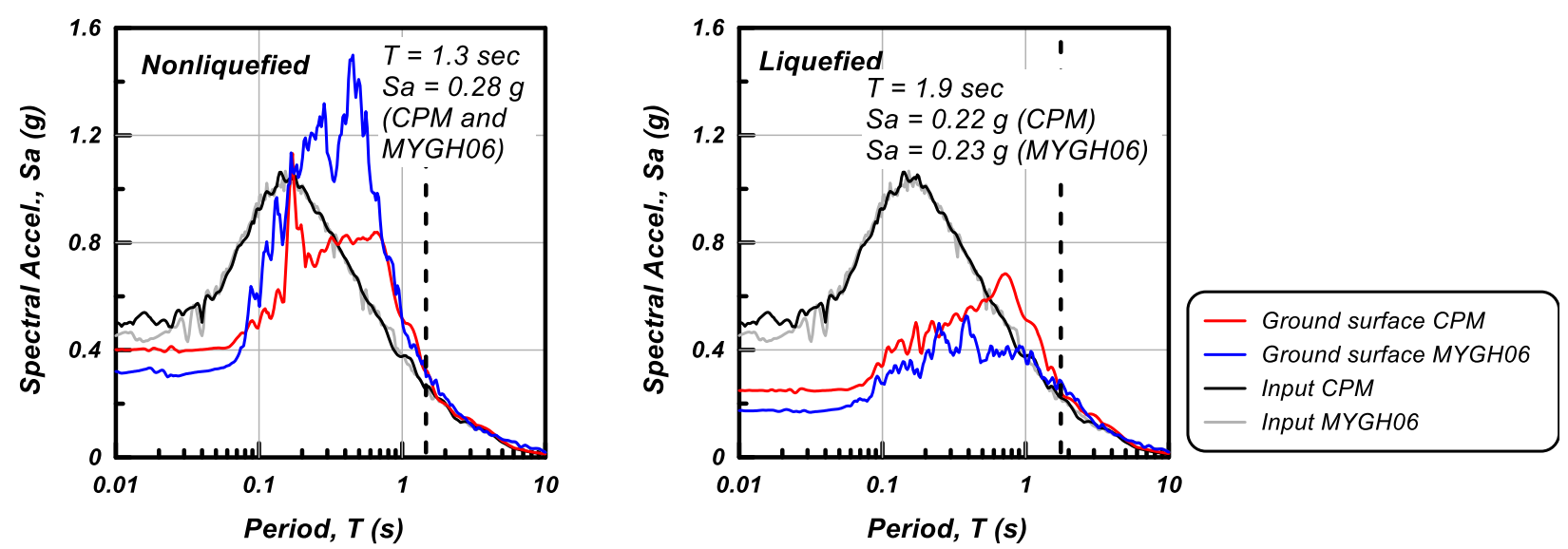

Figure 5. Input and ground surface spectral accelerations in liquefied and nonliquefied conditions for CPM (short duration) and MYGH06 (long duration) motions.
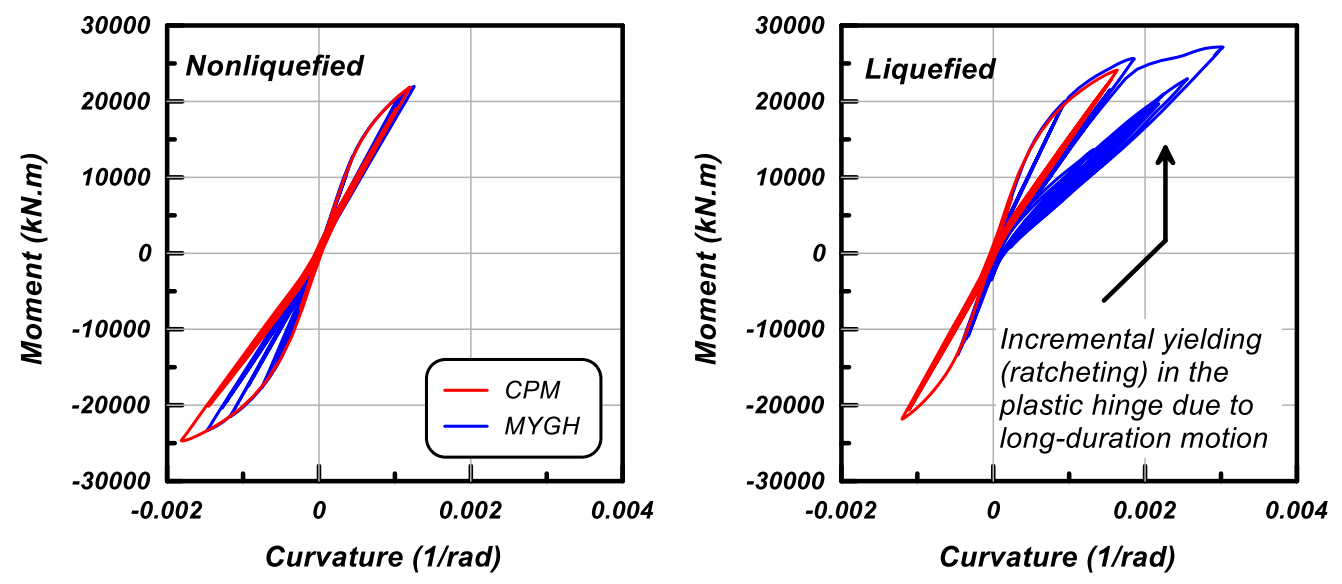

Figure 6. Moment-curvature response in the plastic hinge in liquefied and nonliquefied conditions for CPM (short duration) and MYGH06 (long duration) motions. 


\section{PROPOSED EQUIVALENT STATIC ANALYSIS (ESA)}

A displacement-based ESA method is proposed here for estimating elastic and inelastic pile demands in liquefied conditions. The proposed ESA is similar to the method proposed by Khosravifar et al. (2014b) with modifications for long-duration subduction earthquakes. The proposed method consists of the following steps: (1) Apply kinematic demands by imposing soil displacements to the end-nodes of $\mathrm{p}-\mathrm{y}$ springs to get $\Delta_{\mathrm{LS}}$. Soil displacements can be estimated from simplified procedures, e.g. Idriss and Boulanger (2008). Modify the p-y springs in the liquefied layer using p-multipliers obtained from Caltrans (2012). (2) Estimate $\Delta_{\text {Nonliq }}$ using ESA for nonliquefied conditions (Figure 7a). Estimate the target displacement in the liquefied condition $\left(\Delta_{\text {Liq }}\right)$ from Equation 1. (3) Perform ESA by applying soil displacements to the end nodes of p-y springs and the target displacement calculated from Equation 1 to the pile head (Figure 7b). The pushover curves for liquefied and nonliquefied conditions are shown in Figure 7c.

\section{The Choice of CA}

The parameter $\mathrm{C}_{\Delta}$ was back-calculated from the dynamic analyses using Equation 1 and is plotted in Figure 8 . To account for the uncertainty in estimating $\Delta_{\text {Nonliq }}$, this parameter was estimated from ESA. $\Delta_{\text {LS }}$ was estimated by statically applying soil displacements to the end nodes of p-y springs (i.e. kinematics only). The soil displacements ranged from $0.1 \mathrm{~m}$ to $7 \mathrm{~m}$. The pile head displacements due to kinematics only $\left(\Delta_{\mathrm{LS}}\right)$ remains constant at $0.04 \mathrm{~m}$ for soil displacements greater than $0.4 \mathrm{~m}$, corresponding to fully mobilized passive pressure. The mean $\mathrm{C}_{\Delta}$ is approximately 1.3 for subduction earthquakes (interface and intraslab) and 1.15 for shallow crustal earthquakes. Khosravifar et al. (2014b) found similar results where the mean $\mathrm{C}_{\Delta}$ was of approximately 1.1 for over 2000 shallow crustal ground motions. Their data are plotted on Figure 8 to illustrate the scatter in $\mathrm{C}_{\Delta}$.

\section{Comparison of Pile Demands Estimated from the Proposed ESA and NDA}

Figure 9 shows the comparison of estimated pile demands using the proposed ESA approach with those computed from the dynamic analyses (NDA). This comparison provides a measure of accuracy for the proposed ESA method. While the ESA results compare reasonably well with the NDA results for displacements smaller than 0.4 meter, the ESA estimates become unconservative for displacements larger than 0.4 meter. The pile head displacement of 0.4 meter corresponds to the ultimate pushover force in the liquefied condition, beyond which pile behavior is inelastic (Figure 7c). When the displacements are pushed beyond the ultimate point on the pushover curve, the pile behavior becomes very unstable. It is believed that the monotonic nature of the lateral spreading force (crust load) combined with large cyclic inertial loads could excessively, and irrecoverably deform the pile beyond the yield displacement. While the proposed ESA method becomes unconservative for displacements beyond the yield point, this method provides a means 
to identify deformations beyond which pile response becomes unstable and potentially unconservative. For these cases, an equivalent static analysis (ESA) does not accurately predict the pile demands and nonlinear dynamic analysis (NDA) is required.

(a)

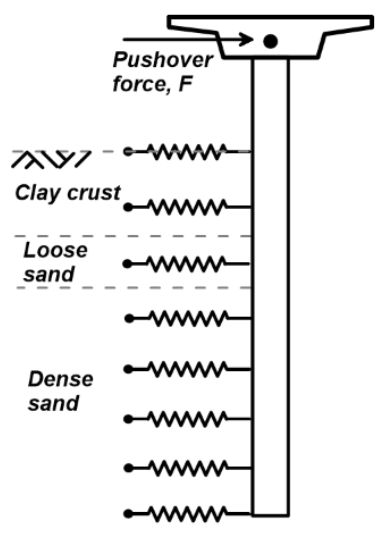

(b)

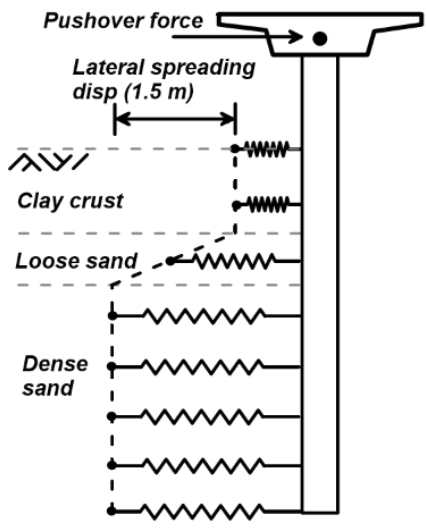

(c)

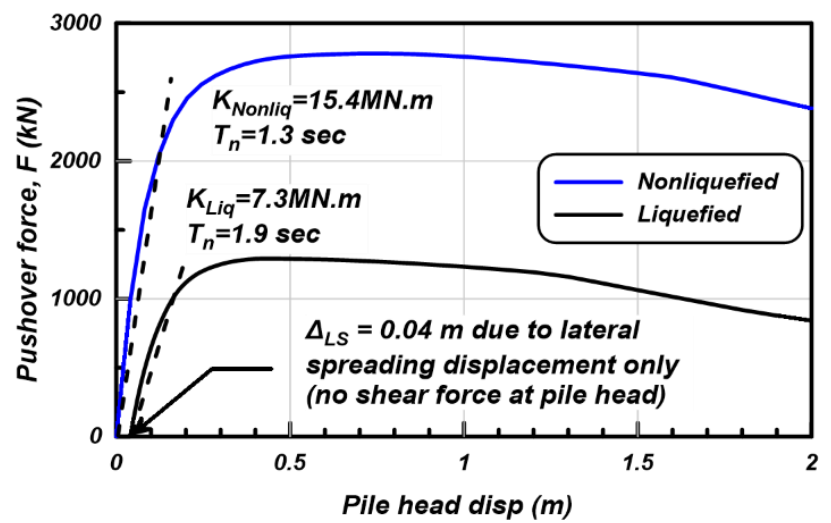

Figure 7. (a) Schematic of pushover model for nonliquefied conditions, (b) pushover model for liquefied condition, and (c) pushover curves for liquefied and nonliquefied conditions

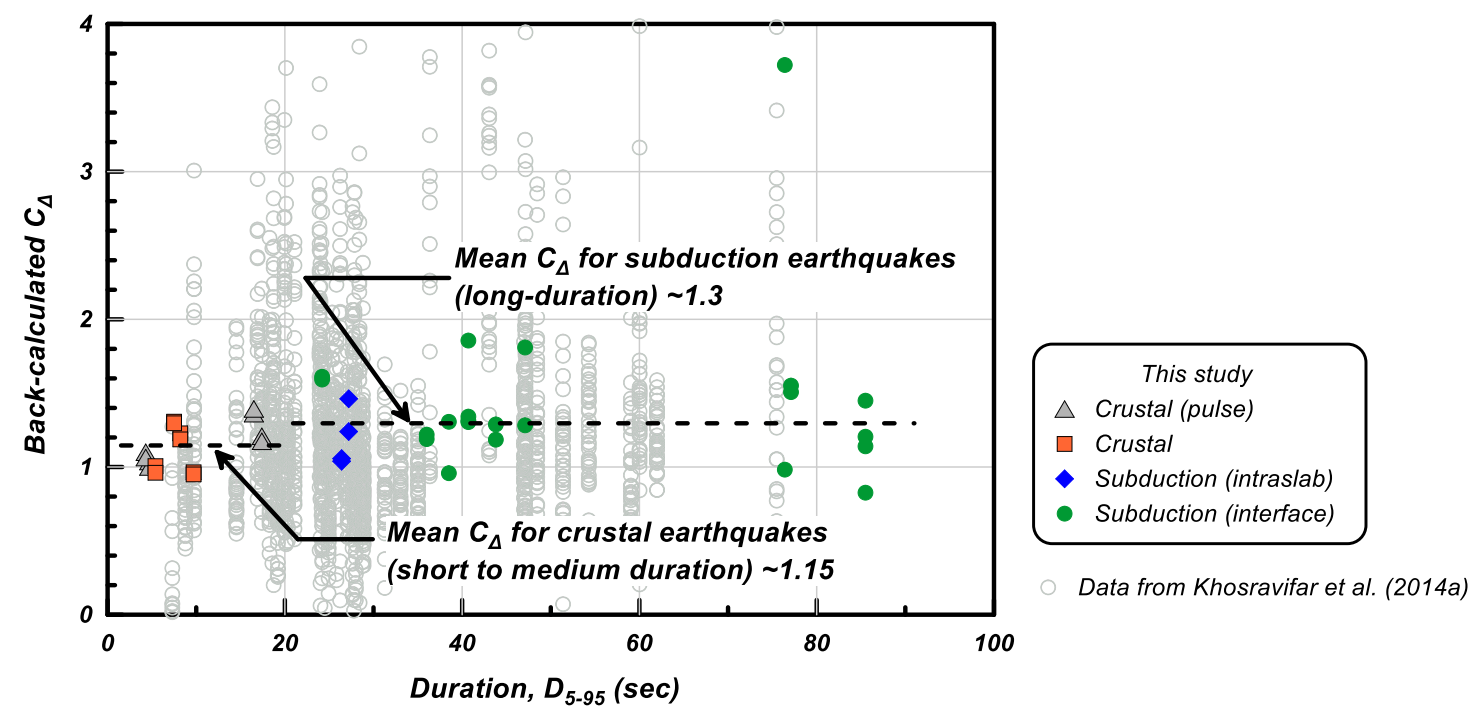

Figure 8. Dependence of $\mathrm{C} \Delta$ (back-calculated from dynamic analysis) to ground motion duration (D5-95) for subduction and shallow crustal earthquakes 


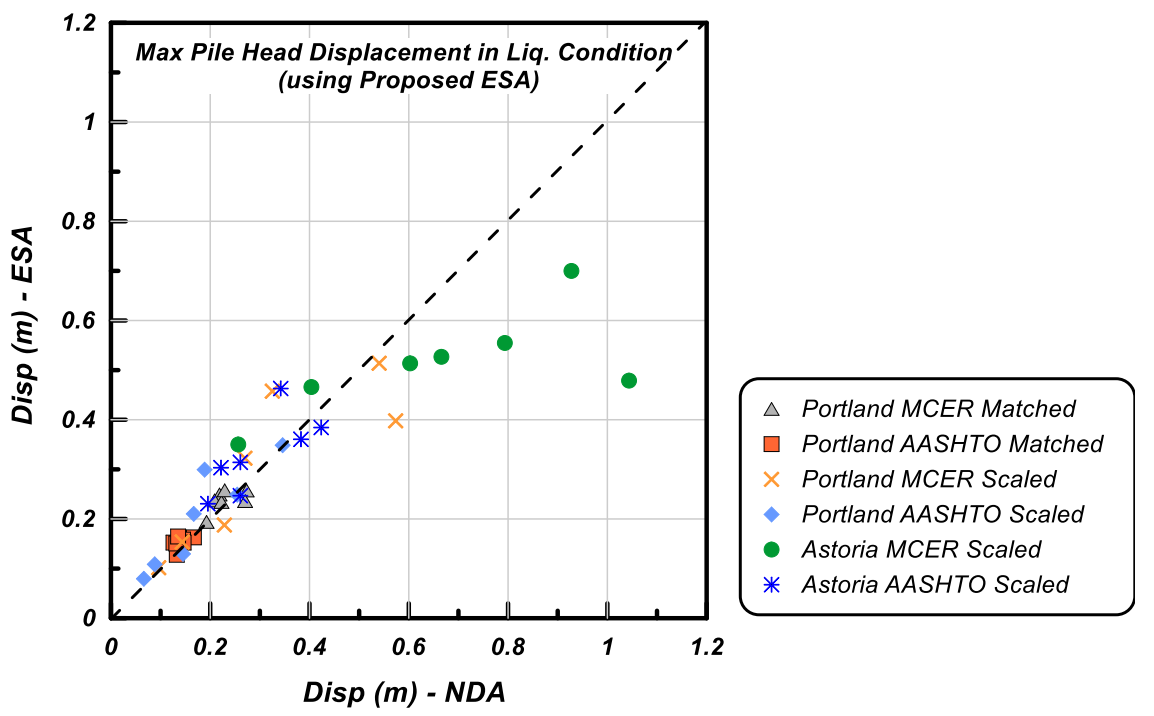

Figure 9. Comparison of the maximum pile head displacements estimated using the proposed ESA method with the NDA results.

\section{CONCLUSIONS}

Effective-stress, nonlinear dynamic analyses (NDA) were performed for a 2-meter diameter RC pile in multi-layer liquefiable soil in sloped ground. A suite of scaled and matched motions covering short to long durations (D5-95 ranges from 4 to $85 \mathrm{sec}$ ) were used. The NDA results showed that pile demands increase in liquefied conditions compared to nonliquefied conditions due to the interaction of inertia and kinematics. An equivalent static analysis (ESA) procedure was developed based on target pile head displacements. The procedure specifically addresses amplification of inelastic demands in long-duration earthquakes. The proposed ESA compared reasonably well against the results of NDA for elastic piles but the accuracy of the method decreases as piles enter the inelastic region.

\section{ACKNOWLEDGEMENTS}

Funding was provided by the Deep Foundations Institute. The authors appreciate the comments by the project advisory board: Dr. Zia Zafir, Dr. Azadeh Bozorgzadeh, and Professor Anne Lemnitzer.

\section{REFERENCES}

AASHTO (2014). "Guide Specifications for LRFD Seismic Bridge Design.” Second Edition with 2014 Interim, AASHTO, Washington, D.C.

American Petroleum Institute (2000). "Recommended Practice for Planning, Designing, and Constructing Fixed Offshore Platforms." API recommended practice 2A-WSD (RP 2AWSD), 21st Edition, API, Washington, D.C., December. 
ASCE/COPRI 61-14 (2014). "Seismic Design of Piers and Wharves, prepared by the ASCE Standards Comm. on Seismic Design of Piers and Wharves." ASCE, Reston, VA.

Ashford, S.A., Scott, M.H., and Rayamajhi, D., (2012). "Reducing Seismic Risk to Highway Mobility: Assessment and Design Examples for Pile Foundations Affected by Lateral Spreading", ODOT Report.

Boulanger, R.W., Chang, D., Brandenberg, S.J., Armstrong, R.J., and Kutter, B.L. (2007). "Seismic design of pile foundations for liquefaction effects." 4th International Conference on Earthquake Geotechnical Engineering, The Netherlands, 277-302.

Brandenberg, S.J., Zhao, M., Boulanger, R.W., and Wilson, D.W. (2013). "p-y Plasticity Model for Nonlinear Dynamic Analysis of Piles in Liquefiable Soil.” ASCE JGGE, 139(8), 12621274.

California Department of Transportation (Caltrans) (2012). "Guidelines for Foundation Loading and Deformation Due to Liquefaction Induced Lateral Spreading." Sacramento, CA.

Idriss, I. M., and Boulanger, R. W., (2008). Soil liquefaction during earthquakes, Monograph MNO-12. Earthquake Engineering Research Institute, Oakland, CA, 261 pp.

Khosravifar, A., and Boulanger, R. W., (2010). Inelastic Response of Extended Pile Shafts in Laterally Spreading Ground during Earthquakes. Deep Foundation Institute J. 4, 2, 41-53.

Khosravifar, A., Boulanger, R.W., and Kunnath, S.K. (2014a). "Effects of Liquefaction on Inelastic Demands of Bridge Pile Shafts.” Earthquake Spectra, 30 (4), pp, 1749-1773.

Khosravifar, A., Boulanger, R. W., and Kunnath, S. K. (2014b). "Design of Extended Pile Shafts for the Effects of Liquefaction.” Earthquake Spectra, 30 (4), pp, 1775-1799.

Mazzoni, S., McKenna, F., Scott, M. H., and Fenves, G. L., (2009). Open system for earthquake engineering simulation user manual. University of California, Berkeley.

MCEER/ATC (2003) "Recommended LRFD Guidelines for the Seismic Design of Highway Bridges." MCEER/ACT 49, Multidisciplinary Center for Earthquake Engineering/Applied Technology Council Joint Venture, University at Buffalo, Buffalo, NY.

Mejia, L.H., and Dawson, E.M. (2006). "Earthquake Deconvolution for FLAC." Proceedings of Fourth International FLAC Symposium on Numerical Modeling in Geomechanics, Madrid, Spain.

Nasr, J.A. (2017). "Development of a Design Guideline for Bridge Pile Foundations Subjected to Liquefaction Induced Lateral Spreading.” M.S. Thesis, Portland State University

Oregon Dept. of Transportation (2014). Geotechnical Design Manual. Tech. Services Branch, Salem, OR

Washington Dept. of Transportation (WSDOT) (2015). “Geotech Design Manual.” M 46-03.11, May 2015

Yang, Z., Elgamal, A., and Parra, E., (2003). "Computational model for cyclic mobility and associated shear deformation.” J. Geotech. Geoenviron. Eng, 129, 12, 1119-1127. 